Tropical Journal of Pharmaceutical Research April 2017; 16 (4): 811-818

ISSN: $1596-5996$ (print); 1596-9827 (electronic)

(C) Pharmacotherapy Group, Faculty of Pharmacy, University of Benin, Benin City, 300001 Nigeria.

All rights reserved.

Available online at http://www.tjpr.org

Original Research Article

http://dx.doi.org/10.4314/tjpr.v16i4.10

\title{
Simple and efficient expression of codon-optimized mouse leukemia inhibitory factor in Escherichia coli
}

\author{
Dewei Niu ${ }^{1}$, Qiuhong $\mathrm{Wu}^{1,2}$, Luyuan Huang ${ }^{3}$, Enze Yang ${ }^{1}$, Meiyan Huang ${ }^{1}$, Yong \\ $\mathrm{Liu}^{4}$ and Feng Wang ${ }^{1 *}$ \\ ${ }^{1}$ Institute of Genomic Medicine, College of Pharmacy, Jinan University, Guangzhou 510632, ${ }^{2}$ Department of Pharmacy, \\ Maternal and child health care Hospital of Zaozhuang, Zaozhuang $277100,{ }^{3}$ Guangdong Provincial Key Laboratory of Stem Cell \\ and Regenerative Medicine, Key Laboratory of Regenerative Biology, South China Institute for Stem Cell Biology and \\ Regenerative Medicine, Guangzhou Institute of Biomedicine and Health, Chinese Academy of Sciences, Guangzhou 510530, \\ ${ }^{4}$ Guangdong Key Laboratory of Agro-Environment Integrated Control, Guangdong Institute of Eco-Environmental and Soil \\ Sciences, Guangzhou 510650, China
}

${ }^{*}$ For correspondence: Email: jnubiopharm@126.com; Tel: 0086-15360022165

Received: 9 September 2016

Revised accepted: 10 March 2017

\begin{abstract}
Purpose: To obtain a higher yield of mouse leukemia inhibitory factor to maintain the proliferation potential of pluripotent stem cells at a low cost.

Methods: A method was designed to produce recombinant mLIF protein (rmLIF) in Escherichia coli. Through analysis of rmLIF sequence, it was found that rare codons were interspersed. After mutation from rare codons to Escherichia coli (E. coli) preferred ones were selected, the mutated gene $\mathrm{mLIFm}$ was cloned into $p E T 15 b$ vector. The $p E T 15 b-m L I F^{m}$ was then transformed into Rosetta-gami strain and induced with optimal conditions at $18{ }^{\circ} \mathrm{C}$ for $16 \mathrm{~h}$. Mass spectrometry was carried out to identify the peptides.

Results: After purification, the yield of the codon-optimized $\mathrm{rmLIF}$ was $141 \mathrm{mg} / \mathrm{L}$, compared with 110 $\mathrm{mg} / \mathrm{L}$ for the original $\mathrm{rmL}$ IF. Mass spectral analysis showed the presence of four major peptides each with an intensity > $10 \%$ at $\mathrm{m} / \mathrm{z}$ 1031.57, 1539.82, 1412.01 and 2229.10 in $\mathrm{mLIF}^{\mathrm{m}}$, respectively. Histagged $\mathrm{rmLIF}$ fusion protein displayed the potential to maintain the morphology of undifferentiated mouse embryonic stem cells (mESCs), which were positive for mESCs markers (Oct-4, Nanog, Sox-2, stage-specific embryonic antigen-1).

Conclusion: The findings provide a means to produce $\mathrm{mLIF}$ in a short, useful, cost-effective and environmentally-friendly manner, and thus lays a foundation for further studies of mLIF.
\end{abstract}

Keywords: Leukemia inhibitory factor, Mutated gene, Protein expression, Purification, Stem cells, Peptides, Escherichia coli

Tropical Journal of Pharmaceutical Research is indexed by Science Citation Index (SciSearch), Scopus, International Pharmaceutical Abstract, Chemical Abstracts, Embase, Index Copernicus, EBSCO, African Index Medicus, JournalSeek, Journal Citation Reports/Science Edition, Directory of Open Access Journals (DOAJ), African Journal Online, Bioline International, Open-J-Gate and Pharmacy Abstracts

\section{INTRODUCTION}

Leukemia inhibitory factor (LIF) is a pleiotropic glycoprotein and a member of interleukin (IL)-6 family. It induces mouse myeloid leukemic M1 cells of terminal differentiation into macrophages [1]. A number of studies have shown that LIF is a multi-purpose cytokine with range of pleiotropic actions on different types of cells and tissues. Not only does it facilitate early embryogenesis and blastocyst implantation of mammals, it also induces the production of acute phase proteins by lipocyte formation and hepatocytes [2,3]. Furthermore, LIF is known as a significant growth factor for maintaining embryonic stem cells and inducing pluripotent stem cells in a pluripotent 
status [4]. LIF is routinely added to the medium of pluripotent stem cells and without LIF leads to a fast differentiation of pluripotent stem cells. Therefore, it is extensively employed in the culture of pluripotent stem cells [5]. The cells play a primary role in cell therapies and tissue replacement therapies [6,7]. Recently, rhLIF was successfully produced and purified by several groups using different kinds of expression systems such as E. coli [8-10], yeast cells and even in rice [11]. An issue arising from this process is the soaring cost of LIF and other cytokines in pluripotent stem cells research. Numerous studies have suggested that the cost of commercially produced LIF accounts for about $90 \%$ pluripotent stem cells culture medium [8]. It is urgent to obtain various forms of LIF in high quantities and at a low cost and biological active.

E. coli is a commonly used host for expression of heterologous protein, but has a marked preference for certain codons. Differences in preference for codons between prokaryotes and eukaryotes can seriously affect protein production in E. coli. Rare codons exist in cloned genes that can affect many aspects such as protein expression and mRNA. Moreover, rare codons correlate with a small number of homologous tRNA in host cells.

In the present study, a cDNA encoding LIF from mice was cloned and sequenced. Subsequently, we developed an effective method to produce soluble rmLIF $^{\mathrm{m}}$ in $E$. coli after mutation from rare codons to $E$. coli preferred ones was performed. This method allowed rapid and effective purification of rmLIF $^{\mathrm{m}}$ in a soluble and biologically active form.

\section{EXPERIMENTAL}

\section{Reagents}

$\mathrm{T}_{4}$ DNA ligase, Sma I and SYBR were purchased from Takara (Tokyo, Japan). FBS, L-glutamine and $\beta$-mercaptoethanol, minimum essential amino acids were purchased from Gibco (Karlsruhe, Germany). Goat anti-mouse IgG Goat anti-mouse IgGs (containing horseradish peroxidase label), anti-Oct-4 and anti-Nanog were purchased from Santa Cruz Biotechnology (Santa Cruz, USA). E. coli cells were purchased from Novagen (New York, USA). The other reagents were commercially available.

\section{Analysis of codons and amino acid sequences of $\mathrm{mLIF}$}

BLASTP program was used to search for homologs of mouse LIF from other species.
Different LIF sequences were compared using the Clustal $X$ program. The rare codons of mLIF were analyzed. In addition, the relationship between mouse LIF and other previously described mammal LIF were showed by a phylogenetic tree, which was constructed using the program Phylip-3.69.

\section{Cloning the coding sequence of mLIF into expression vector}

PCR was used to amplify the coding region of the mouse leukemia inhibitory factor with the cDNA of mouse embryonic fibroblast (MEF) cells as a template. The forward primers (5'GTTCTGCACTGGAAACACG-3') and the reverse (5'-CTAGAAGGCCTGGACCACC-3') were designed based on the mRNA sequence of mouse leukemia inhibitory factor (NM_008501).

The $\mathrm{mLIF}^{\mathrm{m}}$ sequence which mutated from rare codons to $E$. coli preferred ones, was directly synthesized by Invitrogen Company. The mLIF and $\mathrm{mLIF}^{\mathrm{m}}$ were ligated into the modified expression vector pET15b (Sma I) using T4 DNA ligase.

\section{Expression, purification and western blot analysis of rmLIF $^{\mathrm{m}}$}

E.coli Rosetta-gami cells harboring expression plasmids were incubated at $37{ }^{\circ} \mathrm{C}$ until $\mathrm{OD}_{600}$ reached 0.6. IPTG was then added at a concentration of $0.5 \mathrm{mM}$. Subsequently, the culture was shaken constantly at $180 \mathrm{rpm}$ for 16 $\mathrm{h}$ at $18^{\circ} \mathrm{C}$. The supernatant and precipitate were harvested by centrifugation $(12,000 \mathrm{rpm}$ for 10 $\mathrm{min})$. The supernatant was loaded onto a $5 \mathrm{~mL}$ $\mathrm{Ni}$-NTA-His binding column equilibrated with 10 $\mathrm{mM}$ imidazole $(20 \mathrm{mM}$ sodium phosphate $\mathrm{pH} 7.4$, $500 \mathrm{mM} \mathrm{NaCl}$ ). The protein bound matrix was washed with $20 \mathrm{mM}$ imidazole $(20 \mathrm{mM}$ sodium phosphate $\mathrm{pH} 7.4,500 \mathrm{mM} \mathrm{NaCl})$. The protein was eluted with $250 \mathrm{mM}$ imidazole $(20 \mathrm{mM}$ sodium phosphate $\mathrm{pH} 7.4,500 \mathrm{mM} \mathrm{NaCl}$ ). The concentrated sample was tested by BCA assay.

Protein sample of the $\mathrm{rmLIF}^{\mathrm{m}}$ was separated on SDS-PAGE, followed by transfer onto a PVDF membrane. The PVDF membrane was blocked for $1.5 \mathrm{~h}$ at $25 \stackrel{\circ}{\circ} \mathrm{C}$. It was then incubated with mouse anti-His $\lg$ antibody (1:1000) at room temperature. After $2 \mathrm{~h}$, the PVDF membrane was incubated with goat anti-mouse IgG conjugated with horseradish peroxidase $(1: 1000)$ for $1.5 \mathrm{~h}$ at room temperature. After incubation, the specific protein bands were developed using the diaminobenzidine (DAB) system. 


\section{Mass spectrometry analysis}

Sequencing grade modified trypsin (Promega, Madison, USA) was used to digest samples, matrix-assisted laser desorption/ionization timeof-flight mass (MALDI-TOF-MS) was used to analyze samples by an ABI 4800 Plus MALDI TOF/TOF Analyzer (Invitrogen, Carlsbad, USA). IPI mouse database was used to analyze the result (V3.36) by GPS Explore software (V3.6, Invitrogen, Carlsbad, USA).

\section{Maintenance of mouse embryonic stem cells (MESCS) in culture}

We expanded the mouse embryonic stem cells line OG2 which was cultivated on mitomycin C handled mouse embryonic fibroblast (MEF) feeders. The culture medium was composed of DMEM (HyClone, Bonn, Germany) supplemented with $200 \mathrm{mM}$ L-glutamine, $0.1 \mathrm{mM}$ sodium bicarbonate, $0.1 \mathrm{mM} \beta$-mercaptoethanol, $0.1 \mathrm{mM}$ nonessential amino acids, $10 \%$ FBS (all from Gibco, Karlsruhe, Germany) and $100 \mathrm{U} / \mathrm{mL}$ penicillin/streptomycin (Invitrogen, Camarillo, USA). The purified $\mathrm{rmLIF}^{\mathrm{m}}$ was added to the culture medium at a final concentration of 10 $\mathrm{ng} / \mathrm{mL}$. $1000 \mathrm{U} / \mathrm{mL}$ of commercially available mouse leukemia inhibitory factor (Millipore, Billerica, USA) was used as positive control to compare function and efficiency [12].

\section{Real-time PCR}

RNA was extracted from 5 passages of mESCs with each mLIF supplementation. The expression of embryonic stem cell markers was investigated by Real-time PCR and primers were designed as: Oct-4 (FP-TAGGTGAGCCGTCTTTCCAC, RP- GCTTAGCCAGGTTCGAGGAT), Sox-2 (FPAGGGCTGGGAGAAAGAAGAG,RP-CCGCGAT TGTTGTGATTAGT), Nanog (FP- CTCAAGTCC TGAGGCTGACA, RP-TGAAACCTGTCCTTGAG TGC), GAPDH (FP-AACTTTGGCATTGTGGA AGGGCTCA, RP-TTGGCAGCACCAGTGGATG CAGGGA). For data normalization, the GAPDH was used as a reference gene to analyze the gene quantitatively. The reaction efficiency of primers was estimated by a standard curve. The $2^{-\Delta \Delta \mathrm{Ct}}$ method was used to calculate the expression levels of relative gene [13].

\section{Immunofluorescence}

At the tenth passage of mESC culture (30 - 40 days), cell morphology and the expression of ESC markers by immunofluorescence were used to ensure rmLIF $^{\mathrm{m}}$ functionality. The undifferentiated state of $\mathrm{mESC}$ was determined by immunofluorescence staining with Oct-4
(1:250; Santa Cruz Biotechnology, Santa Cruz, USA), Nanog (1:50; Santa Cruz Biotechnology, Santa Cruz, USA), Sox-2 (1:100; Stem Cell Technologies, Vancouver, Canada), and stagespecific embryonic antigen-1 (1:50; Chemicon, Billerica, USA) $4 \%$ paraformaldehyde was used to fixed the cells. After fixed for $10 \mathrm{~min}$, the cells were washed with PBS 3 times, incubated with blocking buffer containing $0.1 \%$ Triton $\mathrm{X}-100$ and $10 \%$ FBS in a humidity chamber at $37^{\circ} \mathrm{C}$. After $1 \mathrm{~h}$, primary antibody was diluted in blocking buffer and applied for $2 \mathrm{~h}$ at $37^{\circ} \mathrm{C}$, then washed three times. After incubation with secondary antibodies conjugated with TRITC (1:200, Sigma, Santa Cruz, USA) for $1 \mathrm{~h}$ at $37{ }^{\circ} \mathrm{C}$, they were washed twice in PBS, followed by incubation with PBS containing DAPI $(10 \mu \mathrm{g} / \mathrm{mL})$ for $5 \mathrm{~min}$. DAPI stain solution was washed, fluorescence microscope was used to obtain pictures.

\section{Statistical analysis}

Data were expressed as mean \pm standard deviation. The relative expression of Nanog, Oct4 , and Sox-2 relative expressions were analyzed using Student's t-test, only if $p<0.05$ the differences were considered statistically significant. SPSS for Windows software (version 13.0; SPSS Inc, Chicago, IL, USA) was used to analysis the data.

\section{RESULTS}

\section{Sequence of $\mathrm{mLIF}$}

Bioinformatic analysis showed that the mLIF gene contains a 612-bp full open reading frame which encoded a $22.3 \mathrm{kDa}$ protein with a pl of 9.39 .

A signal peptide cleavage site was found between positions 23 and 24 of the mLIF sequence based on SignalP database. Therefore, it encoded a supposed 180 aminoacid mature mLIF of $19.9 \mathrm{kDa}$ with a pl of 9.2 .

The results revealed that full mLIF amino acid sequences showed $75-85 \%$ identities to those from Rattus norvegicus, Bos taurus, Homo sapiens, Pteropus alecto, Sorex araneus, Macaca mulatta (Figure 1A). The phylogenic tree of LIF was established according to the amino acid sequence of selected LIF from different species (Figure 1B), mLIF was initially clustered with Rattus norvegicus LIF.

\section{Rare codons}

Rare codons in $m L I F$ sequence were searched in Rare Codons Calculator (Figure 2A). There were 
four rare Pro codons at positions 13, 62, 115 and 157, three rare lle codons at positions 23, 128 and 182, two rare Arg codons at positions 132 and 167 and one rare Leu codon at position 68 in the $570 \mathrm{bp} m L I F$ sequence encoding mature mLIF. All 10 rare codons in the mLIF sequence were replaced by the preferred codons of $E$. coli, generating the $\mathrm{mLIF}^{\mathrm{m}}$ sequence (Figure $2 \mathrm{~B}$ ).
A
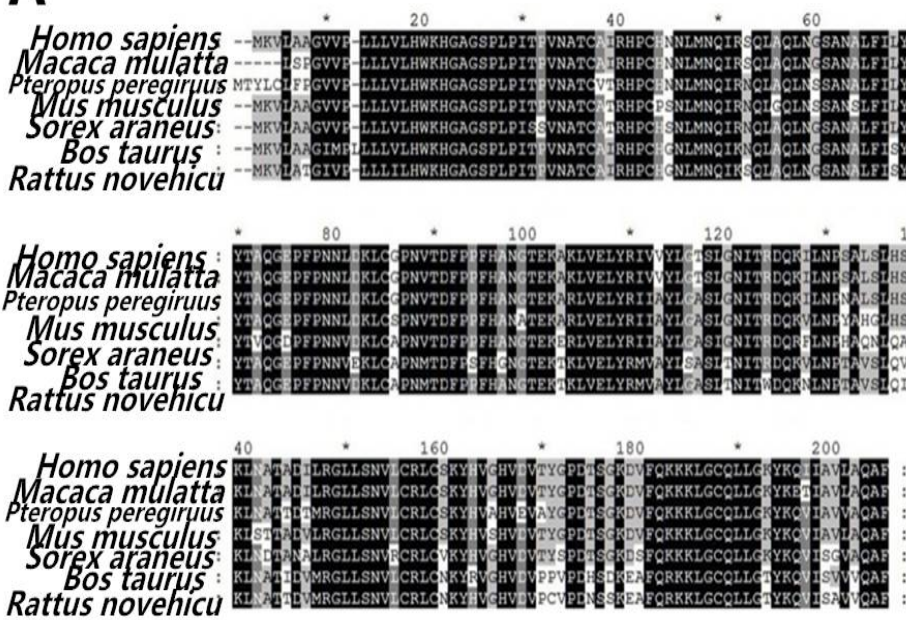

B

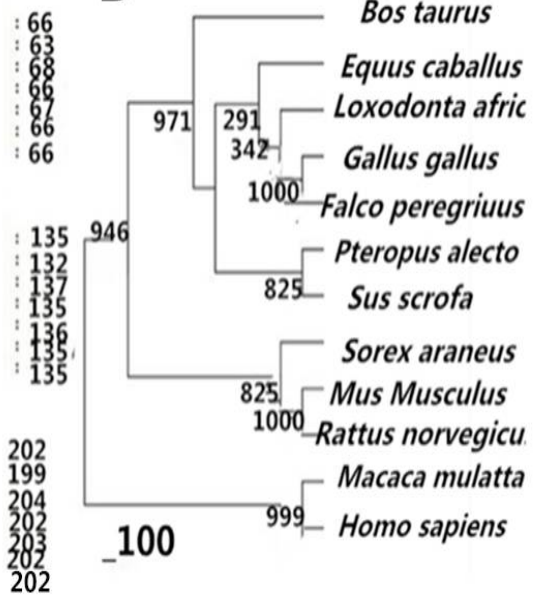

Figure 1: (A) Alignment of amino acid sequences of LIF for mouse and other species. (B) A phylogenetic tree of LIF from different species. It was constructed by Phylip-3.69 program. Numbers represent the values given by bootstrap analysis. The species names (in parenthesis) of different LIF are shown on the right.

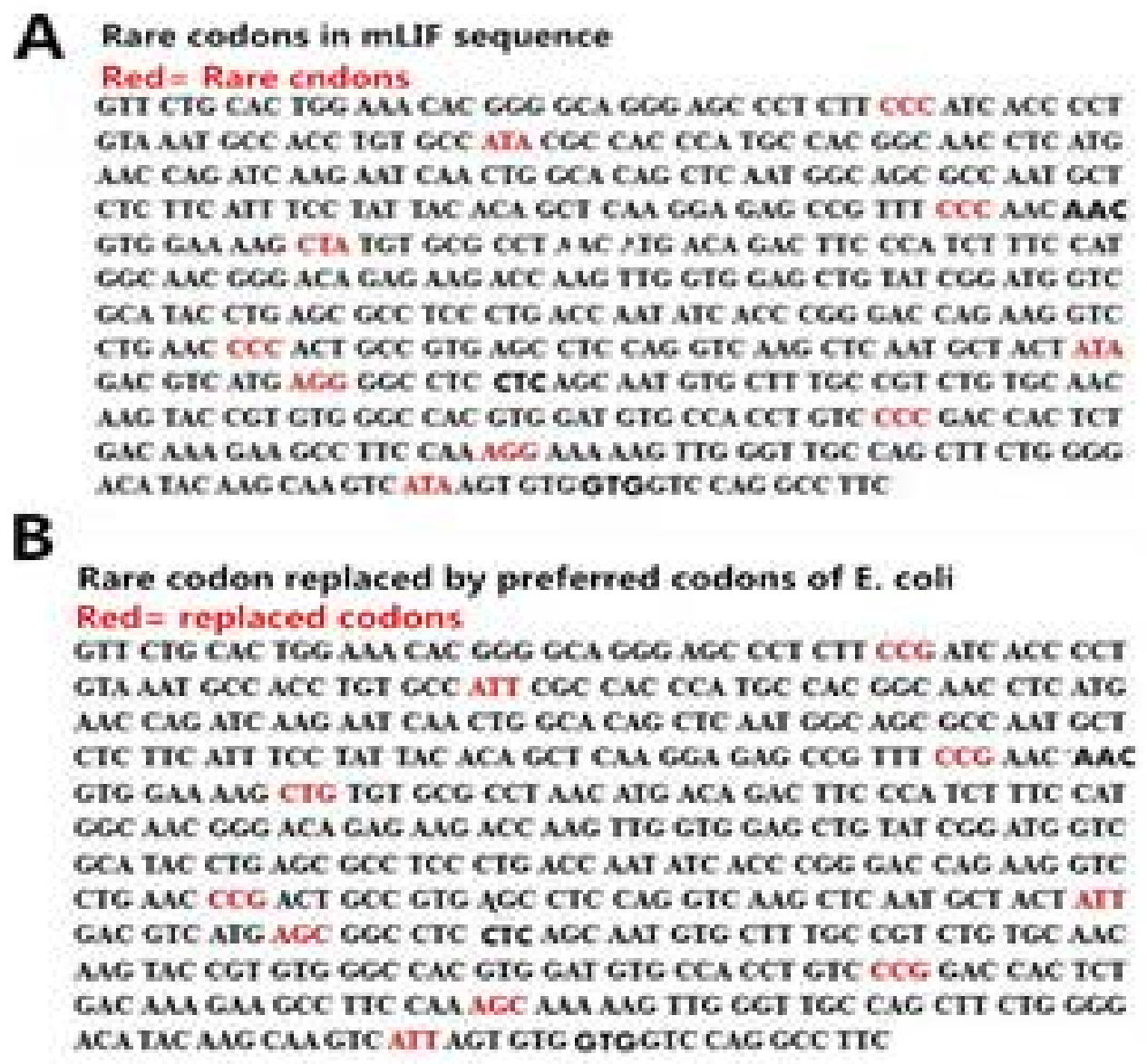

Figure 2: $(A)$ Rare codons in mLIF sequence $(B)$ Rare codon replaced by preferred codons of $E$. coli in $\mathrm{mLIF}^{\mathrm{m}}$ sequence. The codons marked in red were the modified rare codons 
Expression, purity and characteristics of rmLIF $^{\mathrm{m}}$
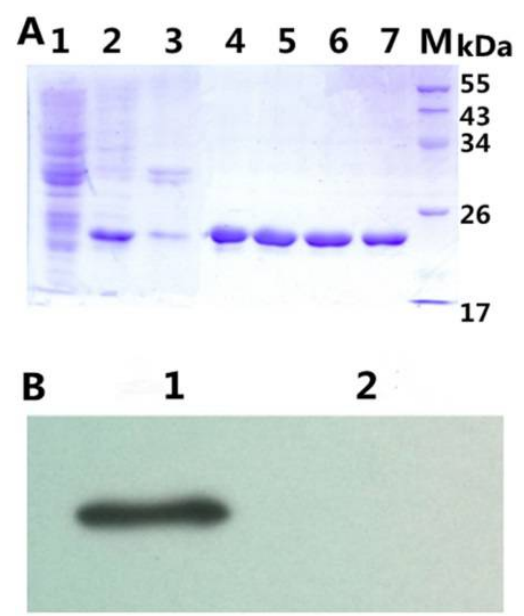

Figure 3: (A) SDS-PAGE analysis of expressed and purified $r m L I F$ and $r m L I F^{m}$ protein. Lane $M$, protein molecular weight standards; lane 1, uninduced E. coli; lane 2, supernatant of rmLIF $^{\mathrm{m}}$; Lane 3 , supernatant of rmLIF; lanes 4 and 5, the purified rmLIF ${ }^{\mathrm{m}}$; lanes 6 and 7, the purified rmLIF $^{m}$ after dialysis. (B)Detection of protein expression by western blot. Lane 1, the purified rmLIF $^{\mathrm{m}}$ protein by Ni-NTA affinity chromatography; lane 2, uninduced $E$. coli lysate

The best optimized conditions for expression of recombinant protein in soluble form was acquired by induction with $0.5 \mathrm{mM} \mathrm{IPTG}$ at $18^{\circ} \mathrm{C}$ for $16 \mathrm{~h}$. Induced culture was harvested which produced $3.2 \mathrm{~g}$ wet weight cells per $500 \mathrm{ml}$ culture. After sonication, the supernatant and pellet was analyzed by SDS-PAGE (Figure 3A). Both rmLIF and $\mathrm{rmLIF}^{\mathrm{m}}$ showed an apparent band about $23.55 \mathrm{kDa}$ after induction. After reforming the rare codons soluble form (Lane 2, Figure 3A) accounts for $35.2 \%$ of total expressed soluble $\mathrm{rmLIF}^{\mathrm{m}}$ in the supernatant of the lysate, compared with rmLIF accounted for only $29.1 \%$ (Lane 3, Figure 3A).

The supernatant was purified by Ni-NTA affinity chromatography. The results showed that the protein had been purified with a purification yield of $97.5 \%$ according to its migration (Figure $3 \mathrm{~A}$ ). The presence of the protein was confirmed with anti-His-tag by Western blot (Figure 3B). As noted in the present study, a tag-based protein purification method was used. The expression level of $\mathrm{rmLIF}^{\mathrm{m}}$ approximated $141 \mathrm{mg} / \mathrm{L}$. Its production increased by one third when compared with the original rmLIF.

\section{Mass spectra}

Figure 4 shows the mass spectrum the trypsin digest of the purified $\mathrm{rmLIF}^{\mathrm{m}}$. There were four major peptides at 1031.57, 1539.82, 1412.01 and $2229.10 \mathrm{~m} / \mathrm{z}$. The strongest peak was appeared on 1412.01, which fit to the predict molecular weight of HGAGSPLPITPVNATCAI peptide fragment. This result was a further confirmation that rmLIF $^{m}$ protein was successfully expressed.

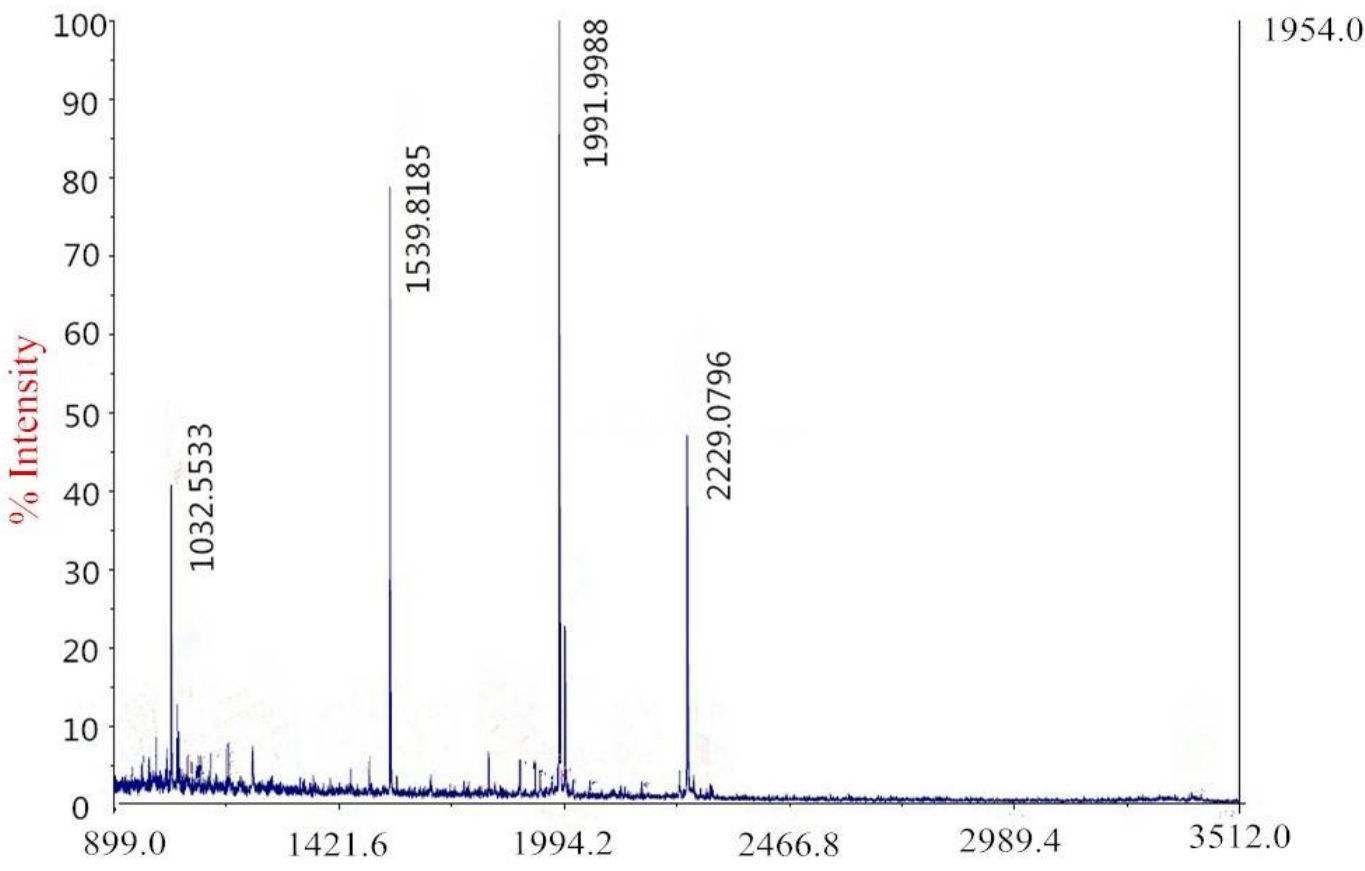

Figure 4: MALDI-TOF mass spectrum of purified rmLIF $^{\mathrm{m}}$. The purified rmLIF ${ }^{\mathrm{m}}$ was determined on SDS-PAGE gel and the rmLIF $^{\mathrm{m}}$ in a piece of gel was subjected to in-gel digestion with trypsin. The resulting polypeptide was analyzed by MALDI-TOF MS 


\section{Biological activity}

The biological activity of rmLIF $^{\mathrm{m}}$ could be identified on account of its ability to maintain the proliferation potential of pluripotent stem cell after numerous passages while retaining their pluripotency $[12,14]$. The results in Figure $5 \mathrm{~A}$ indicated that the group supplied with rmLIF $^{\mathrm{m}}$ expressing the ESCs markers were similar to the positive control group. Importantly, no ESCs markers expression was detected in MEF which were used as a negative control. In addition, after 10 passages in culture, compared with the mESC colonies not treated with $\mathrm{rmLIF}^{\mathrm{m}}$, the group treated with $\mathrm{rmLIF}^{\mathrm{m}}$ fusion protein maintained cell structure integrity, the shape is circular with an intact nucleus, mESC colonies not treated with rmLIF $^{\mathrm{m}}$ were varied and most presented nested or island shapes (Figure 5B). The mESC colonies added to rmLIF $^{\mathrm{m}}$ fusion protein were further detected by immunofluorescence staining with nuclear markers, along with the stage-specific embryonic antigen-1 (SSEA-1), and the results showed that the four stem cell factors were all induced by rmLIFm (Figure 5C).
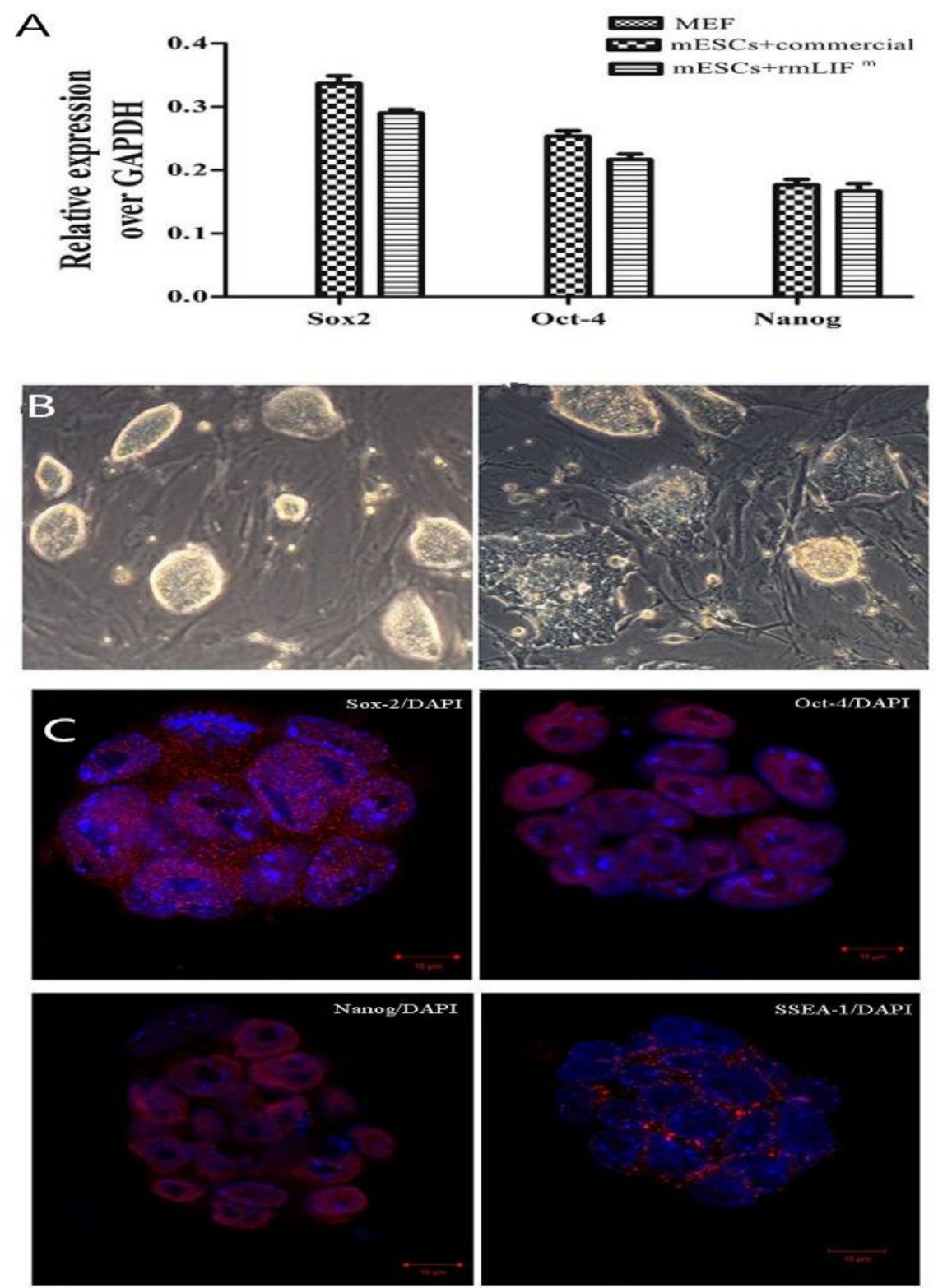

Figure 5: (A) Realtime-PCR analysis of the pluripotent markers, Nanog, Oct-4, and Sox-2 relative expression over GAPDH in mESCs after 5 passages in culture with commercial mLIF, rmLIF ${ }^{\mathrm{m}}$ supplemented media; (B) Morphology of mESCs colonies (phase contrast) after 10 passages in medium containing $10 \mathrm{ng} / \mathrm{mL} \mathrm{rmLIF}$ (left) and not treated with rmLIFm (right); (C) Immunofluorescence imaging of stem cell markers Sox-2 (upper left), Oct-4 (upper right), Nanog (below left) and SSEA-1 (lower right), respectively. DAPI was used to counterstain cell nucleus, Scale bar, $10 \mu \mathrm{m}$ 


\section{DISCUSSION}

To date, a large number of expression systems were used to express LIFs. Among them, majority is hLIF. Low expression yields, misfolds and aggregates, however, prevented laboratories from applying LIF.

Sequence analysis of $m L I F$ demonstrated that there were 10 rare codons in the $570 \mathrm{bp} \mathrm{mLIF}$ sequence encoding mature mLIF which would lower mLIF protein expression levels. In order to overcome the problem of rare codons, we optimized it from rare codons to $E$. coli preferred ones.Although $E$. coli is a helpful host for expression of heterologous protein, differences in codon usage preference between the original organism and E. coli could lead to significant reduction in expression level [15]. Similar reports showed that replacing rare codon increased the expression of beta-G glucosidase by 2- and 3.6fold [16].

A major drawback would be that expression of heterologous protein in large quantities in E. coli often leads to the formation of inclusion bodies [17]. Most of the protein were expressed as inclusion bodies at $37^{\circ} \mathrm{C}$. Along with the form of inclusion bodies, there are usually complicated and unstable refolding procedures which tend to bring about low purification yields [18]. To solve this problem, we used the optimal induction temperature at $18 \stackrel{\circ}{ } \mathrm{C}$, the protein was expressed mostly as a soluble form. Lower temperature makes it easy to form correct protein folding and increase protein solubility [19]. On the other hand, $\mathrm{mLIF}^{\mathrm{m}}$ protein contains three disulfide bonds formed by six conserved cysteine residues [20]. The Rosetta-gami host strain also carried the trxB/gor mutations, which could enhance disulfide bond formation. Our study also demonstrates that the $\mathrm{rmLIF}^{\mathrm{m}}$ produced had correct folding structure. Furthermore, this approach took advantage of the small flexible $\mathrm{N}$ terminal six His affinity tag system for easy purification of fusion protein tagged with a polyhistidine sequence. Compared with other tags, Glutathione S-transferase (GST) and thioredoxin ( $\operatorname{Trx})$ which can improve solubility and yields, it is small enough to not alter functional properties of the tagged proteins and maintain biological activity of recombinant proteins.

As noted in the present study, we used an affinity tag-based purification method to make the purification easy. Meanwhile, soluble $\mathrm{mLIF}^{\mathrm{m}}$ protein can easily be obtained and its expression level rose to approximately $141 \mathrm{mg} / \mathrm{L}$ per $1 \mathrm{~L}$ medium. In contrast with previous study, the yield of rmLIF $^{\mathrm{m}}$ protein was higher. $1.3 \mathrm{mg} \mathrm{hLIF}$ were got from $3.8 \mathrm{~g}$ cells (wet weight) of $1 \mathrm{~L}$ culture by Jung et al [21]. About $30 \mathrm{mg}$ untagged hLIF per $1 \mathrm{~L}$ EnBse Flo culture was achieved after onestep eXact ${ }^{\mathrm{TM}}$ affinity chromatographic purification by Imaizumi et al [10]. Furthermore, Western blot and mass spectrometry were used to identify rmLIF $^{\mathrm{m}}$ fusion protein.

As demonstrated, purified rmLIF $^{\mathrm{m}}$ was helpful in maintaining the multiplication potential of mESCs throughout numerous passages. These results indicated that $\mathrm{mESCs}$ with $\mathrm{rmLIF}^{\mathrm{m}}$ protein treatment showed common multipotent markers. The undifferentiation potential of pluripotent stem cells can be maintained after long-term culture with rmLIF $^{m}$. More importantly, His-tag portion showed no significant effect on the bioactivity of $\mathrm{rmLIF}^{\mathrm{m}}$. Production is cost-effective in bacteria culture. In addition, the protein purification methodology is simple, practical and costeffective which may decrease rmLIF $^{m}$ costs to a large extent.

\section{CONCLUSION}

By adopting optimizing codons, using small molecular weight His tags and prokaryotic host Rosetta-gami, a straightforward and effective method to produce large amounts of soluble $\mathrm{mLIF}^{\mathrm{m}}$ is presented. The strategy not only provides an effective and fast way to produce rmLIF $^{\mathrm{m}}$ which is not only helpful in maintaining the multiplication potential of mESCs and retaining their pluripotency, but also might be useful for the production of other growth factors.

\section{DECLARATIONS}

\section{Acknowledgement}

This research was supported by Science and Technology Planning Project (no. 2012KJCX0017).

\section{Conflict of Interest}

No conflict of interest associated with this work.

\section{Contribution of Authors}

The authors declare that this work was done by the authors named in this article and all liabilities pertaining to claims relating to the content of this article will be borne by them.

\section{Open Access}

This is an Open Access article that uses a fund- 
ing model which does not charge readers or their institutions for access and distributed under the terms of the Creative Commons Attribution License (http://creativecommons.org/licenses/by/ 4.0) and the Budapest Open Access Initiative (http://www.budapestopenaccessinitiative.org/rea d), which permit unrestricted use, distribution, and reproduction in any medium, provided the original work is properly credited.

\section{REFERENCES}

1. Gough NM, Gearing DP, King JA, Willson TA, Hilton DJ, Nicola NA, Metcalf D. Molecular cloning and expression of the human homologue of the murine gene encoding myeloid leukemia-inhibitory factor. Proc Natl Acad Sci 1988; 85(8): 2623-2627.

2. Taupin J-L, Pitard V, Dechanet J, Miossec V, Gualde N, Moreau J-F. Leukemia inhibitory factor: part of a large ingathering family. Int Rev immunol 1998; 16(3-4): 397 426.

3. Auernhammer C, Melmed S. Leukemia-Inhibitory Factor-Neuroimmune Modulator of Endocrine Function 1. Endocr Rev 2000; 21(3): 313-345.

4. Williams RL, Hilton DJ, Pease S, Willson TA, Stewart $C L$, Gearing DP, Wagner EF, Metcalf D, Nicola NA, Gough NM. Myeloid leukaemia inhibitory factor maintains the developmental potential of embryonic stem cells. Nature 1988; 336(6200): 684-687.

5. Donaldsonili DD, Wongtli GG, Moreau J, Stahli $M$, Rogersi D. stem cell differentiation by purified polypeptides. Nature 1988; 336: 15.

6. Cheng L, Hammond H, Ye Z, Zhan X, Dravid G. Human adult marrow cells support prolonged expansion of human embryonic stem cells in culture. Stem cells 2003; 21(2): 131-142.

7. Cormier J, zur Nieden $N$, Rancourt $D$, Kallos $M$. Expansion of undifferentiated murine embryonic stem cells as aggregates in suspension culture bioreactors. Tissue Engg 2006; 12(11): 3233-3245.

8. Tomala M, Lavrentieva A, Moretti $P$, Rinas U, Kasper $C$, Stahl F, Schambach A, Warlich E, Martin U, Cantz T. Preparation of bioactive soluble human leukemia inhibitory factor from recombinant Escherichia coli using thioredoxin as fusion partner. Protein Expr Purif 2010; 73(1): 51-57.

9. Gearing DP, Nicola NA, Metcalf $D$, Foote $S$, Willson TA, Gough NM, Williams RL. Production of leukemia inhibitory factor in Escherichia coli by a novel procedure and its use in maintaining embryonic stem cells in culture. Nature Biotechnol 1989; 7(11): 1157-1161.
10. Imaizumi K, Nishikawa S, Tarui H, Akuta T. High-level expression and efficient one-step chromatographic purification of a soluble human leukemia inhibitory factor (LIF) in Escherichia coli. Protein Expr Purif 2013; 90(1): 20-26.

11. Youngblood BA, Alfano R, Pettit SC, Zhang D, Dallmann $H G$, Huang $N$, Macdonald CC. Application of recombinant human leukemia inhibitory factor (LIF) produced in rice (Oryza sativa L.) for maintenance of mouse embryonic stem cells. J Biotechnol 2014; 172: 67-72.

12. Miller RA, Britigan BE. Role of oxidants in microbial pathophysiology. Clinical Microbiolo Rev 1997; 10(1): 118.

13. Makrides SC. Strategies for achieving high-level expression of genes in Escherichia coli. Microbiol Rev 1996; 60(3): 512-538.

14. Niwa H, Burdon T, Chambers I, Smith A. Self-renewal of pluripotent embryonic stem cells is mediated via activation of STAT3. Genes Dev 1998; 12(13): 20482060.

15. McKown RL, Raab RW, Kachelries $P$, Caldwell S, Laurie GW. Conserved Regional 3 ' Grouping of Rare Codons in the Coding Sequence of Ocular Prosecretory Mitogen Lacritin. Investigative Ophthalmol Visual Sci 2013; 54(3): 1979-1987.

16. Shim JH, Withers SG. Improvement of the Expression Level of beta-Glucosidase from Agrobacterium $s p$ in Escherichia coli by Rare Codon Optimization. Food Sci Biotechnol 2013; 22(1): 269-273.

17. Moore JT, Uppal A, Maley F, Maley G. Overcoming inclusion body formation in a high-level expression system. Protein Expr Purif 1993; 4(2): 160-163.

18. Feng W, Mei S, Wenjie $Y$, Luyuan H. High-level soluble expression of recombinant human manganese superoxide dismutase in Escherichia coli, and its effects on proliferation of the leukemia cell. Protein Expr Purif 2011; 77(1): 46-52.

19. Slice $L W$, Taylor S. Expression of the catalytic subunit of cAMP-dependent protein kinase in Escherichia coli. Journal of Biological Chemistry 1989; 264(35): 2094020946.

20. Nicola NA, Cross B, Simpson RJ. The disulfide bond arrangement of leukemia inhibitory factor: homology to oncostatin $M$ and structural implications. Biochem Biophys Res Commun 1993; 190(1): 20-26.

21. Song JA, Koo BK, Chong SH, Kim K, Choi DK, Thi Vu TT, Nguyen MT, Jeong B, Ryu HB, Kim I, et al. Soluble expression of human leukemia inhibitory factor with protein disulfide isomerase in Escherichia coli and its simple purification. PLoS One 2013; 8(12): e83781. 